\title{
Eyes Complete Response GvHD
}

National Cancer Institute

\section{Source}

National Cancer Institute. Eyes Complete Response GVHD. NCI Thesaurus. Code C126701.

An NIH eye score of 0 after previous GvHD involvement. 